\title{
Local explanation in historiography of science
}

\author{
Veli Virmajoki ${ }^{1}$
}

Received: 6 February 2020 / Accepted: 18 September 2020 /Published online: 6 October 2020

(C) The Author(s) 2020

\begin{abstract}
In this paper, I offer an explication of the notion of local explanation. In the literature, local explanations are considered as metaphysically and methodologically satisfactory: local explanations reveal the contingency of science and provide a methodologically sound historiography of science. However, the lack of explication of the notion of local explanation makes these claims difficult to assess. The explication provided in this paper connects the degree of locality of an explanans to the degree of contingency of the explanandum. Moreover, the explication is shown to be compatible with the methodological need for a general consideration in the historiography of science. In this way, the explication (i) satisfies the need to explicate an important notion, (ii) connects local explanations and contingency, and (iii) enables us to see how local explanations and general considerations can be connected. However, the explication also sheds critical light on many claims and expectations that are associated with local explanations and their satisfactoriness.
\end{abstract}

Keywords Localism · Local explanation · Contingency $\cdot$ Generalizations · History and philosophy of science $\cdot$ Philosophy of historiography

\section{Introduction}

The notion of local explanation is a topic of wide interest in the historiography of science. James Secord writes:

As will be evident to anyone who has looked over publishers' catalogues in recent years, historians of science have developed superb techniques for placing science in local settings of time and place. A standard model for historicizing science is to locate specific pieces of work in as tight a context as possible, binding them ineluctably to the conditions of their production. $(2004,657$.)

Veli Virmajoki

vevirm@utu.fi

1 University of Turku, Verkapiha 1 as 24, 20100 Turku, Finland 
Moreover, Peter Galison notes that "the turn toward local explanation in the historical, sociological, and philosophical understanding of science may well be the single most important change in the last thirty years" $(2008,119)$. What is striking is that, despite the general historiographical interest in local conditions and despite all the philosophical discussion ${ }^{1}$ about the notion of explanation, a detailed analysis of the notion of local explanation cannot be found in the literature of historiography of science. ${ }^{2}$

In this paper, I analyze the notion of local explanation to see whether local explanations can live to up to the expectations that have been placed upon them. The discussion places the notion of local explanation in a wider philosophical perspective and suggests that local explanations are not quite as groundbreaking as has been suggested. In order to get the discussion going, we need to take a closer look on (i) the existing characterizations of local explanation, (ii) the expectations that historians of science have regarding that category of explanation, and (iii) the problems that arise from (i) and (ii). ${ }^{3}$

We need to begin our analysis from the characterization of local explanation. JouniMatti Kuukkanen has provided the most explicit characterization that can be found in the literature. He writes: "In general and as a first approximation, [local explanation] refers here to all the positions that regard science and/or scientific knowledge as local in some sense, or explains them by reference to locally existing factors. "(2012, 478). Kuukkanen also argues that the idea behind the local focus is "that a science constructed in a locality reflects that locality and possesses different characteristics from a science conducted in another. This thought also has fundamentally changed how one explains the practice of science." (2011, 591.) The problem is that, unless we understand what is meant by notions such as "explains by reference to locally existing factors" or "science reflects a locality", the notion of local explanation remains unclear. To illustrate this, consider that someone argues that, because everything exists somewhere (i.e. everything has some location), it follows that every explanation cites only locally existing factors. This kind of "trivial localism" surely cannot ground what is taken to be one of the important changes in the historiography of science. We need a precise approach to local explanation. In Section 2, I will provide an explication of the notion of local explanation that captures the explanatory role of locations in contrast to other kinds of factors and thus avoids the trivialization of the notion. However, the explication must also be such that it enables us to understand why local explanations are considered as attractive and how they can live up to the expectations that historians have placed upon them.

It seems that local explanations are attractive for two reasons. First, local explanations are viewed as "metaphysically" satisfactory as they seem to describe in detail how science works. ${ }^{4}$ A very important aspect of this satisfaction seems to follow from the

\footnotetext{
${ }^{1}$ Including the recent philosophy of historiography of science, see Isis 110 (2).

${ }^{2}$ An anonymous referee suggested that there could be interesting connections between local explanations and categories such as "contextual explanation". I cannot discuss the issue here but it is worth mentioning that the notion of local explanation could be analyzed further by explicating these connections.

${ }^{3}$ As I focus on the conceptual aspects of local explanation, I do not focus on the question of how locally produced science became global. This question has often been asked in connection with local explanations (see Galison 1997; Secord 2004; Kuukkanen 2011), but it seems difficult to see how the question could be answered before we understand what local explanations amount to in the first place.

${ }^{4}$ I use "metaphysical" here in a relaxed way to refer to the idea that local explanations do not explain only their intended explananda but also show something (allegedly) deep about science and human practices in general.
} 
expectation that local explanations provide us with a perspective on the contingency or even the fragility of science. Lorraine Daston writes:

Probably most historians of science these days, if asked about an episode [--] would answer that such scientific practices are both socially constructed and real. [They] capture some aspect of the world; they work. But they are neither historically inevitable nor metaphysically true. Rather, they are contingent to a certain time and place yet valid for certain purposes. [2009, 813. emphasis added]

Also Kohler and Olesko argue that:

This understanding [that science is a product of the society that creates and harbors it] was achieved not by abstract reasoning [--] but empirically, by detailed study of local sites of knowledge making. These showed concretely how scientific findings were the products of particular local situations and communal practices with all their historical and social contingencies. (2012, 3 [emphasis added])

This relationship between local explanations and the contingency of science is not just a byproduct of the localist historiography. The wonder that contingency produces is great motivation for localist studies:

The contemplation of historicity - of the sheer singularity of places and times, situations and conjunctures, including all those you habitually take for granted will help you see that there are different ways of looking at the world, and that what is obvious in one perspective may be ridiculous in another. (Rée 1991, 961.)

This connection between localism and contingency seems especially interesting from the point of view of philosophy of science, given the attention that philosophers have paid to the issue of contingency of science and to the possible consequences that the contingency of science would have on our conception of science (see Soler et al. 2015; Kinzel 2015). If local explanations indeed reveal the contingency of science, then it is no wonder that they received much attention and we should be able to capture the workings of such explanations. (However, see the critical remarks, at the end of the next section, which consider the relationship between local explanations and the philosophical issue of contingency.)

Secondly, it has been claimed that local explanations are epistemologically preferable to their alternatives. Kuukkanen argues that.

[On] the methodological level, the essence of localism can be said to be its rejection of a priorism in historical studies of science. It is a movement for more intensive empiricism which, as a consequence of this, rules universalism out as an inaccurate and unwarranted description of science $(2012,481)$. 
According to universalism, "science and at least some of its production conditions are universal" (ibid, 487). ${ }^{5}$ Kuukkanen argues that "[the methodological localism studies] bounded localities in order to acquire knowledge that would otherwise be difficult to formulate or be without proper warrant" $(2012,478)$. Local explanations are not just a better way to understand what happened in a particular location but they also carry the promise of "well corroborated (general) knowledge, the validity of which extends beyond a particular locality" (Kuukkanen 2012, 484).

Because local explanations are seen as attractive due to their connection to the contingency of science and methodological considerations, the explication of the notion of local explanation I provide in the next section is built in a way that makes these connections explicit. The explication (i) interprets locality as a matter of degree, and (ii) connects (but does not equate ${ }^{6}$ ) the degree of locality of an explanans to the degree of contingency of the explanandum. My argument is that if we assume that there is a connection between local explanations and contingency, then the notion of local explanation must be understood in a particular way to guarantee that connection. Notice that what are described as local explanations in the literature may not satisfy the explication given here. This also means that the historiographical studies that claim to establish the contingency of science by local explanation may not achieve much on that front. This is a very natural consequence, since the more expectations we have, the more difficult it is to live up to those expectations. The discussion concerning the connection between local explanations and contingency therefore enables us to put the grandiloquent claims about the power of local explanations into perspective.

Moreover, I argue (in Section 3) that the methodological status of local explanations is not as clear as is supposed. I will point out three fundamental roles that generalizations and general considerations play in the historiography of science as a field. Without generalizations and general considerations, the methodology of historiography of science remains inadequate. We need to be careful when explicating the notion of local explanation in order to keep the explication compatible with the need for such generalizations and considerations. The caution stems from the fact that, while generalizations require that factors fall into general categories, local explanations seem to put so much focus on a particular context that the general categories seem irrelevant and therefore the factors in the context are easily treated as unique. To establish my own explication, I will argue that strong localism, "a form of particularism, according to which only particular or individual objects exist, and therefore, there are no universals [-], conditions in which science is produced are unique" (Kuukkanen 2012, 485), is not compatible with generalizations and general considerations. Moreover, I argue that the explication offered in this paper differs from strong localism and this allows us to capture both the uniqueness of locations and the need for general considerations. I do this by distinguishing between unique causal configuration and conceptual uniqueness.

\footnotetext{
${ }^{5}$ It is difficult to say whether anyone has been advocating universalism in its pure form. Even Larry Laudan, to mention only one example, in his defense of rationality-based explanations in historiography of science leaves room for what he calls "cognitive sociology" (1977, 208). (An anonymous referee pointed out that "cognitive sociology" may well be universal. Be that as it may, Laudan seems to think that "cognitive sociology" is not applicable to every scientific case (see 1977, 208).)

${ }^{6}$ I.e. providing a local explanation is not the only way to show the contingency of an outcome. Local explanation is sufficient but not necessary for revealing the contingency, according to the explication that will be given.
} 
I argue that we can be localists by insisting upon unique causal configurations but not by holding on to conceptual uniqueness.

I proceed as follows. In Section 2, I provide an explication of local explanation that captures the idea that such explanations show that some events could not have happened in some (relevant) alternative locations. My strategy is to take a general account of explanation and use that account to explicate how the local in the local explanation can be understood. ${ }^{7}$ This explication captures the idea that local explanations show how science was contingent on the actual location where it was produced; i.e. that certain locations are unique in their causal configuration with respect to a historical development of science. In Section 3, I argue that even though local explanations, in the sense of Section 2, do play a role in the historiography of science, it would be a mistake to think that historical locations are conceptually unique; i.e. that they cannot be described by using general categories. In fact, I argue that the properties of historical locations must be described by using general categories in order to occur in explanations. As a conclusion, I argue that once we distinguish between unique causal configuration and conceptual uniqueness, the tension between localism and universalism can be broken and the value of both positions appreciated: Universalism is correct in insisting upon the use of general categories but wrong in denying unique causal configurations, whereas localism is correct in underlining unique causal configurations but wrong if it insists upon conceptual uniqueness.

As my aim is to show how the notion of local explanation must be understood if we want local explanations to live up to the expectations that has been placed on them, my explication is going to be somewhat revisionary. The explication does not intend to capture fully how the notion of local explanation is in fact used (i.e. the logic behind explanations that are casually called "local") but how it must be used so that it can be connected with the notion of contingency and with the methodological issues in the historiography of science. However, I will illustrate this with an example from the historiography of science so that the explication can be closely connected with the existing historiography.

\section{Local explanations and the contingency of science}

In James Woodward's theory of explanation, "the underlying or unifying idea in the notion of causal explanation is the idea that an explanation must answer a what-ifthings-had-been-different question, or exhibit information about a pattern of dependency" $(2003,201) .^{8}$ According to the theory, explanations answer questions of the form "Why X rather than Y?" by pointing out factors Z and W such that "had W rather than $\mathrm{Z}$ been the case, $\mathrm{Y}$ rather than $\mathrm{X}$ would have been the case". 9 Explanations provide information about counterfactual dependencies between explanans and explanandum

\footnotetext{
7 This implies that, in my account, local explanations do not differ in their logical structure from other explanations. The difference is in what changes are seen as relevant.

${ }^{8}$ One should not be afraid of the terminology of "causal explanation". Elsewhere (Virmajoki 2020) I have argued that Woodward's theory can incorporate intentional and narrative explanations in historiography.

${ }^{9}$ I have modified the terminology for the purposes of this paper. In Woodward's theory, an explanans consists of (i) a value(s) of a variable(s) and (ii) a "test-invariant" explanatory generalization. Explanations relate changes in the explanans-variables to changes in the explanandum-variable. (Woodward 2003, 403).
} 
and are contrastive in nature. For the purposes of this paper, it is enough if we consider explanations as answers to questions of the form "What should have happened so that $\mathrm{Y}$ [i.e. counterfactual alternative] rather than $\mathrm{X}$ [i.e. what actually happened] would have been the case?" An example: Why did I eat oatmeal rather than bread? - Because there was oatmeal rather than bread in my kitchen; had there been bread, I would have eaten bread.

Let $\mathrm{C}$ be the set of all factors $\mathrm{f}_{1} \ldots \mathrm{f}_{\mathrm{n}}$ such that: had any of these factors (or any subset of them) ${ }^{10}$ been different, $\mathrm{Y}$ rather than $\mathrm{X}$ would have been the case. $\mathrm{C}$ explains, as it answers what-if-things-had-been-different questions (or more briefly: what-if questions). We can assume that all the factors in $\mathrm{C}$ exist locally (i.e. that trivial localism is true). However, it does not follow that the location of a factor is always an explanatorily relevant dimension. (I will give an example below). We need to capture the explanatory relevance of the location of the factors.

What we want to capture is the idea that $\mathrm{X}$ happened because certain factors were present in the location where $\mathrm{X}$ happened. However, we do not want to define localism as the thesis that had the causes of X not existed, X would not have happened. This claim is trivial. Instead, we want to capture the idea that had some of X's causes existed somewhere else (for example, in another research environment or in a different cultural setting), ${ }^{11} \mathrm{X}$ would not have happened: In order for $\mathrm{X}$ to happen, the causal factors needed to occur in the location where they actually occurred and changing their location would have led to a different outcome. However, we do not want to say that localism implies that every change what-so-ever in the location of factors would have led to a different outcome). This would be analogous to saying that the amount of income does not affect the well-being of an individual if it is possible that two different income-levels result in the same amount of well-being. Clearly, the amount of income is the cause of well-being as long as there exists some relevant change in the income that changes the well-being. ${ }^{12}$ (See Woodward [2003, Section 2.5] for analysis.) In the same way, the location of a factor is explanatory and relevant as long as it is true that, in some cases, a relevant change in the location of a factor would have changed the outcome. Let us make this train of thought more precise, step-by-step:

Let CL denote the subset of all the factors in C such that: had any of these factors (or any subset of them) been located differently, Y rather than X would have been the case. CL answers what-if questions and therefore explains. Then we can say that:

(Initial explication of Unique Causal Configuration): The more factors there are in CL, the more local is the explanation of' Why X rather than Y?"

\footnotetext{
${ }^{10}$ It is possible that changing $f_{1}$ alone does not change $X$ to $Y$ but changing both $f_{1}$ and $f_{2}$ does. If this is the case, then we need to treat " $f_{1}$ and $f_{2}$ " as if they were one factor. For example, when we discuss "the plausibility of a change of location" below, we need to consider the scenarios where both $\mathrm{f}_{1}$ and $\mathrm{f}_{2}$ are located differently. These technicalities do not matter much for the purposes of this paper. My hope is that the example below about the invention of calculus clarifies the point.

${ }^{11}$ We should not think of locations merely as spatial locations. In the current analysis, we can allow a location to mean whatever historical research considers as a location.

12 If Tyson Fury lost all his money, his well-being would probably drop. However, if he received 100 pounds more from his victory, this would probably not affect his well-being.
} 
Take an example (1): Why was a wallet picked up on a street in New York? There are many factors, including: because the wallet was in the location $\mathrm{L}$ and because there were people in $\mathrm{L}$. The location of the wallet does not belong to CL whereas the crowd in L does belong. Had the wallet been on a different street, it would still have been picked up; had there been no-one on the location L (had the people been somewhere else), the wallet would not have been picked up.

Next, consider second example (2): Why did an ornithologist spot a rare bird in New York? There are many factors, among them: because the bird was in location L and because the ornithologist was in L. Both factors belong to CL: had the bird been located somewhere else, the ornithologist would not have spotted it; had the ornithologist been located somewhere else, the bird would not have been spotted.

Notice that the degree of locality may change due to the way we formulate the explanandum. If we ask "Why was the rare bird spotted in New York?" and assume that there are many ornithologists in New York, then it may not be true that had the ornithologist been located differently, the bird would not have been spotted, as someone else could have spotted the bird. However, in this paper we can take as given that, in any given case, the explanandum is fixed and can focus only on analyzing the degree of locality of the explanation of such fixed explanandum. Moreover, it must be noted that one can always "build in" the locality into an explanation by choosing an explanandum with the form "Why did X happen in the location L?" but it would be an error to think that all (or even a significant number of) interesting explananda have this form. ${ }^{13}$ The formulation of explanandum is therefore important to keep in mind when discussing local explanations, but locality does not reduce to any tricks that we can perform with such formulations.

Notice also that the explication above is not very specific. If we change the location of the ornithologist by $1 \mathrm{~m}$, she would have spotted the bird anyway; and had the wallet been at the bottom of the ocean, it would not have been picked up. Some changes in the locations affect the outcome while others do not. We have to make the explication more detailed:

Let $\mathrm{P}_{\mathrm{f}}$ denote the set of locations where a factor $\mathrm{f}$ (that belongs to CL) can be located. Let $\mathrm{P}_{\mathrm{f}}^{*}$ be the subset of $\mathrm{P}_{\mathrm{f}}$ such that had f occurred in a location that belongs to $\mathrm{P}_{\mathrm{f}}^{*}, \mathrm{Y}$ would have been the case. We can say:

(Initial explication 2): The more there are $\mathrm{P}_{\mathrm{f}}{ }^{*} \mathrm{~s}$ for the factors in CL, the more local is the explanation of' Why X rather than Y?"

This explication tells us that an outcome depends on local factors if there are many locations such that had an explanatory factor been located there, the outcome would have been different. To give a rather simplified example: that the wallet was picked up depends less on the location than the ornithologist spotting of the bird: the wallet would have been picked up even if it had been dropped inside a building but the ornithologist would not have spotted the bird if she had been inside a building. There are more places where the ornithologist would not have spotted the bird than there are places where the wallet was not picked up.

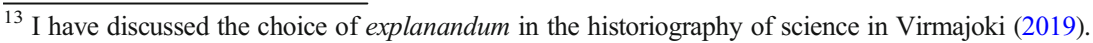


We can notice that only if none of the factors in CL was located in their respective $\mathrm{P}_{\mathrm{f}}$ *s, then the outcome would not have been different. This means that if $\mathrm{P}_{\mathrm{fl}}{ }^{*} \ldots \mathrm{P}_{\mathrm{fn}}$ * involves many locations, then there are many possible changes in the locations of the factors that would have changed $\mathrm{X}$ to $\mathrm{Y}$. If many such changes are possible, then the occurrence of $\mathrm{X}$ seems to have been fragile: it depended on the right occurrence of all the factors in a particular location. This seems to explain the close connection between local explanations and the contingency of science.

However, we need to be somewhat more precise here. Explication of the notion of contingency of science have proved to be an extremely difficult task (e.g. Soler et al. 2015; Kinzel 2015). However, we can say, as a first approximation, that those who take science to be contingent think that science could have been different in some interesting sense. To approach the relationship between contingency and localism, I start from Virmajoki's (2018) explication of contingentism. That explication fits our purposes in this paper because it is based on a counterfactual account of explanation and discusses the contingentism from a historiographical perspective by admitting that, from the historiographical point of view, there are many ways in which science could have been "interestingly different". However, it must be noted that the contingency of science is understood more loosely in Virmajoki's approach than in the philosophical literature. In the philosophy of science, the question is usually about the possibility of a science that is fundamentally different from but equally successful as the actual science, whereas Virmajoki defines the notion of contingency of science without reference to equal success or a fundamental difference in order to capture the variety of things that the historiography of science seeks to explain. This means that even if local explanations reveal the contingency of science in Virmajoki's sense, they may not reveal it in the philosophical sense. I return to this topic at the end of the section.

Virmajoki approaches contingency as follows:

It could have been the case that science has the feature $\mathrm{F}^{*}$ rather than the actual feature $\mathrm{F}$, where the difference between $\mathrm{F}$ and $\mathrm{F}^{*}$ is considered interesting in the given context of discussion.

We can accept that $\mathrm{F}^{*}$ could have been the case if and only if (a) someone points out a counterfactual past event $Z$ that would have led to $F^{*}$, and (b) it is shown that the occurrence of $Z$ in the past is not an impossible (or extremely far-fetched) scenario. $(2018,311)$.

Moreover, contingency is a matter of degree:

Feature $\mathrm{F}$ can be judged to be (a) inevitable if and only if the occurrence of any $\mathrm{Z}$ is seen as impossible and (b) a truly chancy feature if $Z$ is a part of the actual history. Moreover, the more far-fetched the occurrence of $Z$ is judged to be, the more inevitable feature $\mathrm{F}$ is. $(2018,311)$.

In other words, "the best way to approach questions of contingency is to build counterfactual scenarios that would have led to an interestingly different science, and then evaluate the plausibility of these scenarios. [-] we need to know what should have happened in the past in order for there to be some alternative to actual science, and only then evaluate how plausible or far-fetched that occurrence was." (Ibid., 310.) Basically, 
Virmajoki argues here that there are two types of considerations that are relevant in assessing the contingency of some $\mathrm{F}$ (in contrast to $\mathrm{F}^{*}$ ). First, one concerns whether a counterfactual event $\mathrm{Z}$ would have led to $\mathrm{F}^{*}$. In our terminology, the first type of consideration is about what explains "Why F rather than F*?". Second, one concerns whether the occurrence of $Z$ was plausible. We can skip the first type of consideration, as we are analyzing when a given (local) explanation reveals the contingency of science and, in this context, we can take as given that an explanation is provided. So we need to focus on the considerations of the second type. Virmajoki argues that it is difficult to give a general recipe to reach judgement about plausibility of a scenario $(2018,312)$ but illustrates this with an example from the historiography of science that "historians always make these kinds of judgments when explaining historical processes [and] these judgments make sense and can be rationally debated" (ibid.) I accept Virmajoki's view on the issue and follow his procedure by giving an (admittedly brief) illustration of the kind of considerations that bear on the question of plausibility when discussing a historical study in the end of this section.

If we follow Virmajoki, our initial explication does not connect the degree of locality with a degree of contingency. It is possible that there are many factors in CL and yet X was rather inevitable. This is the case if the situations where the factors in CL are located in relevant alternative locations which are not plausible. For example, we can say (contrary to our earlier thoughts) that in the example (1) the location of the wallet could have been such that it was not picked up. If the wallet had been located at the bottom of the ocean (this being wallet's $\mathrm{P}_{\mathrm{f}}^{*}$ ), it would not have been picked up. Here, CL contains two factors: the location of the wallet and the location of a crowd of people. Yet it was not contingent that the wallet was picked up, according to Virmajoki's account. Both a particular street being empty in New York and the wallet ending up at the bottom of the ocean are somewhat implausible scenarios. On the other hand, in the example (2) there are also two factors in CL: the location of the bird and the location of ornithologist. It seems that both the bird being somewhere else and the ornithologist being somewhere else are plausible scenarios. Therefore, the spotting of the bird was highly contingent. Of course, the difference here is a matter of degree. It is not impossible for a wallet to end up at the bottom of the ocean or that a street be empty. However, these are less plausible scenarios than that of an ornithologist or a bird being in different places.

Let $\mathrm{P}_{\mathrm{f}}$ denote the set of locations where a factor $\mathrm{f}$ (that belongs to CL) can be located. Let $\mathrm{P}_{\mathrm{f}}^{*}$ be the subset of $\mathrm{P}_{\mathrm{f}}$ such that had f occurred in a location that belongs to $\mathrm{P}_{\mathrm{f}}^{*}, \mathrm{Y}$ would have been the case. We can say:

(Explication of Unique Causal Configuration): The more plausible it is that some factors that belong to $\mathrm{CL}$ occurred in locations that belong to their respective $\mathrm{P}_{\mathrm{f}}^{*} \mathrm{~s}$, the more local is the explanation of" Why $\mathrm{X}$ rather than $\mathrm{Y}$ ?"

This explication connects the degree of locality with the degree of contingency. Once localism means that a plausible change in the location of some factor would have led to a different outcome, the actual outcome is contingent since, according to Virmajoki, any plausible change that leads to a different outcome makes the actual outcome contingent. Moreover, once the degree of locality is explicated as the degree of 
plausibility of the change of the location of some explanatory factor, the degree of locality is connected to the degree of contingency since, according to Virmajoki, the degree of contingency depends on the degree of plausibility of a change in the explanatory factors.

As we saw, there are outcomes that have a local explanation according to the explication above, such as an ornithologist spotting a rare bird. However, not everything, it seems, has a local explanation. Consider the invention of calculus. This simultaneous invention does not seem to have a local explanation to any significant degree. We can even bracket the intuition that sooner or later calculus would have been invented even in the absence of Newton and Leibniz, and focus on a narrower question "Why did calculus emerge in the late seventeenth century?". One could say that "had Newton not been located in a network of scientists, he would not have invented calculus". The problem is that Leibniz would have. And if Leibniz had not been located in a network of scientists, Newton would still have invented calculus. The only option is to argue that "had both Newton and Leibniz stayed outside a network of scientists, calculus would not have been invented in the late seventeenth century". Assume this is true. Then, in order to establish that the explanation is local to a significant degree, one should establish that a scenario in which both of the thinkers were outside scientific networks is somewhat plausible. If one believes that there is such a plausible scenario (I do not: notice, for example, that a scenario where both men died in their childhood will not do since here the men do not change their locations but are eliminated from the history), then, in order to establish that the invention of calculus simpliciter has a local explanation, one has to provide a plausible scenario in which everyone capable of inventing calculus was not located in a network of scientists. It seems far-fetched to think that such a scenario can be argued for. Finally, notice that if someone argues that "If the scientific networks had been different, for example, if different results had been achieved earlier, then calculus would not have been invented" then one is changing which causal factors existed, not their locations, and we saw earlier that it is trivial to claim that had the causes been different, the outcomes would have been different. It seems that the invention of calculus cannot be explained by a local explanation. These considerations show that the explication of the notion of local explanation above can be used to distinguish local explanations from those that are not local.

But is the explication ad hoc? I do not think so. The explication says that we have a local explanation when a plausible change(s) in the location(s) of a factor(s) would have changed the outcome. Local explanations are supposed to be detailed and concrete. This focus should be extended to the modal sphere and therefore the explanatorily relevant possibilities should be fairly close to the actual course of events. It is disproportional to jump from the actual events to far-fetched scenarios while writing historiography with a detailed local focus. Moreover, if the explication above is ad hoc, then local explanations and the contingency of science are not closely connected. This would not be a worrisome result - it would be rather interesting to notice that local explanations produce only an illusion of a contingency. However, one should wonder what explanatory role locations play if one does not restrict the relevant changes in them. Consider that I wonder why I am still alive. I notice there is a telephone in my room. Then I conclude that the presence of a telephone keeps me alive: had there been a monster rather than a telephone, I would not be alive. This seems an odd way to think. What is the explanatory role of a telephone here? Is it not the absence 
of a monster that is really relevant? Similarly, an explanation citing a far-fetched change in the location of a factor should make one wonder whether the explanatory work is done by something other than the location, perhaps by the fact that the explanatory factor existed in the first place.

A further issue is whether the existing historiography of science that claims to produce local explanations satisfies either the initial or the fully-developed explications and whether the local explanations which claim to point toward the contingency of science satisfy the fully-developed explication. ${ }^{14}$ However, at least sometimes historical explanations satisfy the explications. Let us take an example from the historiography of science to illustrate the issues in this section. In the paper," Distrust and Discovery: The Case of the Heavy Bosons at CERN" (2001), John Krige describes "the microhistorical process whereby different groups of scientific actors [-] came to claim that a new fundamental particle (the $\mathrm{W}$ boson) had been discovered at CERN" (2001, 517). The paper illustrates how factors including the theoretical background, the personal qualities of the scientists, the pressure from the funding agencies, and the competition for prestige affected how the $\mathrm{W}$ boson was discovered and how the results were announced. The microhistorical focus of Krige's study prima facie connects it to the family of local explanations. As Galison's discussion about local explanations points out, a microhistorical explanation is a very typical local explanation $(2008,120)$.

Krige's paper is complex. However, we can focus on (i) the technology at CERN, (ii) the political pressures, (iii) Carlo Rubbia, and (iv) certain decisions. The decision of CERN to search for the $\mathrm{W}$ boson was due to a technological advantage over the competitor, Fermilab, and due to problems with the image of CERN (Krige 2001, 522523). Once that decision was made, the CERN directorate decided to perform two experiments because (i) the most advanced technology was uncertain, because (ii) the political situation required the participation of many scientists and (iii) because the directorate did not trust Rubbia (ibid. 525-528). However, two different experiments did not matter much in the end: Rubbia suddenly decided to publish the results before adequate scientific work had been done to check those results (ibid. 533-535). Once that decision was made, other people were forced to adapt to the situation due to the political and institutional situation (ibid. 535-537).

How local is this explanation? Plausible changes in the location of technology or political processes probably would not have changed the process or the outcome. Scientists would have gathered around the technology, and political information would have travelled anyway. However, suppose that the decision to search for the $\mathrm{W}$ boson had been made in Fermilab. This would have changed the technology used in the experiments and the political and institutional context. Perhaps the $\mathrm{W}$ boson would not have been found; perhaps there the results would never have been published due to lack of clarity in the data. If either of these is a credible outcome, we can say that the location of the decision might be an explanatory factor.

\footnotetext{
${ }^{14}$ For example, Paul Elliot has concluded in one of his papers that "Far from being disembodied, placeless, abstract conceptions, the evolutionary theories of Erasmus Darwin and Herbert Spencer, which through the latter exerted a global influence, were rooted, shaped, and developed in the social, landscape, and industrial character of the English Midland provinces and the scientific communities they nurtured" $(2003,29)$ even though a closer look reveals that, throughout the paper, Elliot describes in detail connections between ideas and worldviews that were moving around Europe.
} 
Moreover, suppose that Rubbia was located somewhere other than CERN. This would have decreased the need for two experiments and probably there would not have been a sudden turn. Without two experiments or Rubbia's maneuvering, the process of experimentation or the outcome could have been different. If either of these is a credible outcome, the location of Rubbia might be an explanatory factor. Moreover, both (i) the change in the location of the decision and (ii) the change in the location of Rubbia seem plausible. Fermilab considered performing the experiment (ibid. 521523 ) and perhaps Rubbia would have worked in that project. ${ }^{15}$ Moreover, human life is contingent, and some event could have affected Rubbia's presence in CERN's experiment. That these scenarios are plausible means that the location of the decision and the location of Rubbia are explanatory factors.

To sum up, we could say that:

It was plausible that the $\mathrm{W}$ boson experiments were performed in Fermilab. Had there been this change in the location of experiments, the $\mathrm{W}$ boson would not have been found (due to technological limitations) or the results would not have been published (due to the lack of political pressure).

It was plausible that Rubbia did not participate in the experiments in CERN. Had Rubbia worked somewhere else, the process would have taken another path and probably led to a different outcome.

Therefore, locations of factors made a difference to the outcome since plausible changes in locations would have changed the outcome.

I hope that this brief discussion indicates that the explication of the notion of local explanation formulated above is neither trivial nor too complex. The discussion also shows how the question of explanatory relevance of locations can be approached in the historiography of science. Many questions concerning the relevance of the locations of the factors in the process leading to the announcement of $\mathrm{W}$ boson were left open but we saw where the answers might be found.

Finally, it must be noted that even if a historiographical explanation satisfies the explication of the local explanation above, that explanation may nevertheless be philosophically uninteresting. There is a simple reason for this: The philosophical question about the contingency of science is about an equally successful but fundamentally different science. Historiographical explanations rarely answer questions with the form "Why does science have the successful feature F rather than the equally successful but fundamentally different feature $\mathrm{F}^{*}$ ?" and therefore remain silent about the philosophical question of the contingency of science. For example, Krige's study discussed above does not give us any reason to think that changing the location of certain factors would have led to a science which posits something fundamentally different from the $\mathrm{W}$ boson. I do not think the discrepancy between the philosophical question of contingency and the contingency that local explanations reveal is a reason to reject the explication. As Virmajoki (2018) argues, there are many interesting questions of contingency in historiography that are not relevant to the philosophical question of contingency - in fact, historians are rarely interested in the philosophical

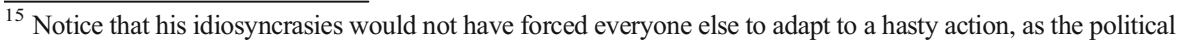
and institutional situation would have been different.
} 
question of contingency. Nevertheless, we are able to see, on the basis of the analysis in this section, how far-fetched it would be to think that a local explanation could provide a philosophically interesting insight into science. In order to connect a local explanation to the philosophical issue of contingency, we should define local explanation along the lines of "Factor $\mathrm{f}$ could have existed in location $\mathrm{L}$ and had it existed there, science would be fundamentally different but equally successful". Clearly, this is not the definition of a local explanation that historians have in mind when they underline the local nature of their studies since hardly any historiographical study satisfies this structure (as far as I am aware). Yet this definition would be needed to justify claims such as.

"[S]cientific practices [--] capture some aspect of the world; they work. But they are neither historically inevitable nor metaphysically true. Rather, they are contingent to a certain time and place yet valid for certain purposes." (Daston 2009, 813 [emphasis added].)

[Historical studies] showed concretely how scientific findings were the products of particular local situations and communal practices with all their historical and social contingencies. (Kohler and Olesko, 2012, 3 [emphasis added].)

The connection between localist studies and the philosophical lessons has been overplayed in the historiography of science. The metaphysical satisfaction of local studies is limited.

\section{The need for generality}

The idea that general laws are needed for causal judgements goes back to at least Hume. Hume thought that every causal judgement is based on an observed regularity, and a singular causal judgement is always an instance of such a regularity (Hume 2007). In the famous covering-law model, general laws must be cited in every explanation (Hempel \& Oppenheim 1948; Hempel 1942). A more subtle thesis is formulated by Davidson: A true singular causal claim is entailed by the premises citing the occurrence of cause and a true causal law, once the cause and effect fall under suitable descriptions $(1967,701)$. We cannot accept these views in their original form in the philosophy of historiography. The views of Hume and Hempel would imply that there are no causal explanations in historiography since there are no laws in history, ${ }^{16}$ whereas Davidson's view would imply that the search for reductive descriptions is the main epistemological task in establishing historiographical explanations. ${ }^{17}$

However, even if we do not accept the views above as they stand, this does not mean that we can have a complete methodology of explanations in the historiography of science without some place for generalizations or general considerations (i.e. considerations that are essentially about kinds of things and relationships between those

\footnotetext{
${ }^{16}$ Or at least the number and nature of laws would be such that they could not ground the variety of explanations in historiography.

${ }^{17}$ Of course, Hempel described historical explanations as "explanation sketches". I see no reason why explanations, having the form presented in the previous section, would not be genuine explanations. See Woodward (2003, 4.9) discussing this issue.
} 
kinds). In this section, I will not examine the general philosophical questions about such generalizations. Rather, I will point out some essential roles that (admittedly weak) generalizations play in the historiographical thinking and in the structure of the historiography of science as a field. Once these roles are explicated, we see that the explication of the notion of local explanation formulated above is a methodologically sustainable explication. In the conclusion, I discuss whether local explanations are methodologically preferable and, if so, preferable to which approach.

To clarify my position, I contrast it with strong localism, "a form of particularism, according to which only particular or individual objects exist, and therefore, there are no universals: [-] conditions in which science is produced are unique" (Kuukkanen 2012, 485). Strong localism implies that there are no categories of (relevant) causal factors and therefore no historiographical (causal) generalizations. ${ }^{18}$ If there were such categories, the conditions would not be unique to the relevant extent, as there would be universals or resemblancerelations that ground the categorization. In other words, strong localism assumes the conceptual uniqueness of historical locations. My argument is the following: Assume that we can write about events in the past and warrant singular causal judgements even in the absence of categories and generalizations. I argue that even in this case we need generalizations, and therefore categories, to direct and control the historiography of science in order to achieve important explanatory ends. In particular, I point out that we need generalizations in order to (i) control the explanatory resources, (ii) make sense of the notion of explanatory depth, and (iii) choose relevant explananda. Therefore, even if strong localism and conceptual uniqueness did not make the world unintelligible (which I doubt), we would still need generalizations. I have chosen to contrast the version of localism formulated above with strong localism rather than universalism since my aim is to clarify the notion of local explanation rather than to defend localism, as indicated in the introduction. However, we will see that my explication will place localism between (crude) universalism and strong localism. I argue that once we move away from strong localism, we adopt some universalist tendencies without accepting that position in its fullness. Universalism says that the development of science can be explained by a very limited set of factors that are applicable to almost every case. While this is unlikely to be true, we will see below that searching for generalizations and widely applicable factors plays an important role in historiography of science. That my position is located between strong localism and crude universalism means that the localism explicated in this paper could also be reached by analyzing the defects of (crude) universalism. However, as universalism is a rather marginal position in the historiography of science, I find the path from strong localism to localism more illuminating.

1. The historiography of science is not an ahistorical practice. It builds on the results of previous studies and there are (and have been) discernible trends in the field. ${ }^{19}$ These developments are not just a mindless river in which the historians swim; they are

\footnotetext{
18 The idea (strong localism) that everything must be explained by locally existing unique factors does not follow from the metaphysical view that only particulars exist. One should establish the additional view that these particulars cannot be categorized. Without such an argument, we can simply continue to categorize them. One may continue a metaphysical inquiry and ask what are the grounds for the categorization (universals? resemblance?), but we stop doing metaphysics here.

${ }^{19}$ One of the most recognized of these trends is that "such ideals as truth, value-neutrality, and objectivity are neither eternally unchanging nor universally accepted. Rather, they are historical constructs, interpreted in a range of different ways, and coming into prominence at particular times for particular reasons. Several important works of historical scholarship have mapped this terrain [--].” (Golinski 2012, 20).
} 
conscious choices. The developments are based on a search for deeper understanding and coherent pictures. Such a search cannot proceed if nothing guides the research questions and unifies the answers.

Let the term explanatory resources denote the set of kinds of factors that can be used in an explanation in the historiography of science. The explanatory resources can be seen as consisting of possible-cause generalizations: they describe what kinds of factors are among the possible explanantia for some event.

The explanatory resources must be restricted. Otherwise they would not serve their role in guiding the kind of questions historians ask and in unifying the answers. ${ }^{20}$ However, the explanatory resources must also be rich (or powerful) enough to guarantee that we can answer many explanation-seeking questions. This means that the explanatory resources must somehow be managed. I suggest the following picture:

The method of managing the explanatory resources is to balance the number of factors that provide an explanatory understanding in particular historiographical cases with the general applicability of those factors. Historians have built a stock of explanations. When novel explanations are formulated, the factors that have worked previously in the historiography should be used as heuristic that drive the ongoing research. If it turns out that those factors are not relevant in the research at hand, new factors must be used. This situation also means that many existing explanations must be re-evaluated in order to avoid inflation in our explanatory resources.

For example, if some developments $D_{1}-D_{n}$ in the history of science have been credited to crucial experiments $(\mathrm{C})$, then new research on a development $\mathrm{D}^{*}$ should check first whether crucial experiments could be used to explain $\mathrm{D}^{*}$. If it turns out that $\mathrm{D}^{*}$ cannot be explained by citing $\mathrm{C}$, then a new factor $\mathrm{F}$ needs to be given. Moreover, historians should also re-evaluate the explanations that were based on the notion of crucial experiment, and the choice of $\mathrm{F}$ should be such that $\mathrm{F}$ can be used to explain a wider set of developments than $\mathrm{C}^{21}$ Otherwise adding $\mathrm{F}$ is ad hoc. In this way, the simplicity and power of explanatory resources can be balanced. We remove one factor from our explanatory resources and replace it with another, presumably more applicable, factor. ${ }^{22}$ The management of explanatory resources is one way to gain secondorder understanding in the historiography of science: We do not learn only about a particular explanandum but about explanations in the historiography of science in general.

Sometimes we do not need a completely new factor but only a modification of the original one. For example, if crucial experiments do not explain anything - if there is no such a thing, logically speaking - we could replace such a factor with "an experiment that made the theory T* need more adjusting than T". This is important since here we have a Davidsonian idea as a methodological tool without commitment to a full-blown

\footnotetext{
${ }^{20}$ Even though the interventionist theory does not share the idea that explaining $\mathrm{X}$ requires that $\mathrm{X}$ is derived from a unified account of a range of phenomena with unificationist accounts of explanations (see Kitcher 1989), having a coherent and well-organized set of explanations for different phenomena, nevertheless it has an important value in explanatory practices of historiography.

${ }^{21}$ This wider set may involve $\mathrm{D}$ and $\mathrm{D} *$ but it can also contain development $\mathrm{D} * *$ besides them. In such cases, we need to re-evaluate the factors that were used earlier to explain $\mathrm{D}^{* *}$. Keeping our resources as strong and simple as possible is therefore a global task.

${ }^{22}$ If no other factor provides better understanding than $\mathrm{C}$, we need further studies.
} 
reductionism: we should seek such new descriptions of factors that keep our explanatory resources as simple and powerful as possible.

Consider an illustration: In the paper, "Inspiration in the Harness of Daily Labor: Darwin, Botany, and the Triumph of Evolution, 1859-1868" (2011), Richard Bellon describes the process that led to the acceptance of Darwin's evolutionary ideas in the British scientific community. Bellon claims that the publication of On the Origin of the Species in 1859 was not a decisive event in this process. On the contrary, the book was judged to be speculative in character and against the scientific and moral standards of the community. Only after publishing a study on orchid fertilization in which he applied his evolutionary ideas, did Darwin's work meet with approval by the community.

Bellon provides an answer to the question:

Why were Darwin's ideas accepted by the British scientific community rather than not?

Bellon gives the following answer:

The Origin was packed with evidence, but it communicated few entirely original scientific observations, and this allowed its critics to dismiss it as vainglorious speculation untethered from the manly discipline of original discovery. [--] If Darwin had not tied the theory of the Origin to productive, technical, and specialized research - in the event, his floral biology, but it could have been any number of things - the ultimate reception and received meaning of the Origin would have been significantly different. [--] science's social, political, and religious respectability depended on the governance of imagination by consistently patient and humble behavior and [--] Darwin's adversaries frequently used this ideology to bludgeon the Origin. Ultimately, Darwin vanquished his foes by reversing the weapon and claiming the mantle of heroic conduct for himself and his theory. (Ibid. 395-396.)

It may seem that the explanation is a rather straightforward one, at least for a philosopher of science. ${ }^{23}$ Darwin first introduced a theory in the Origins, but since the evidence for the theory consisted of "old evidence" rather than of novel discoveries that the theory entails and since novel discoveries are important in the confirmation of a theory, Darwin's theory was not well confirmed and thus not accepted. What is more, his theory had not then been shown to produce what Lakatos would have called a progressive research program and, because it seemed like an improbable candidate to produce one, it was not accepted. Once Darwin published the Orchids, his evolutionary framework proved to be a fruitful research program and to produce novel discoveries and was accepted. Thus, the explanation of the acceptance of Darwin's evolutionary framework can be formulated as follows:

\footnotetext{
${ }^{23}$ This simplified form of analysis can be made, for example, by following Lakatos (1978), Laudan (1977) or Kuhn $(1977,322)$. Needless to say, the discussion about details of confirmation and acceptance of theories and research programs has been enormous.
} 
(E1) Had Darwin not shown in Orchids that this framework was successful and progressive (i.e. fruitful) in empirical research, the evolutionary framework would not have been accepted.

Yet, there is a complication in the issue. Bellon also points out that before the Orchids was published, Darwin's work was dismissed on moral standards. Darwin did not seem to work in a patient, humble and honest manner and, therefore, was not taken seriously (ibid. 403-407). Only after the Orchids, was Darwin accepted as a morally righteous scientist, and therefore the fulfillment of Victorian moral standards was an important factor in the acceptance of his theory. As Bellon points out, the requirements for novel discoveries and progressive research program (i.e. the requirement of fruitfulness) were an embodiment of the Victorian value system and moral standards (ibid 395).

This explanation for the acceptance of Darwin's theory can be framed as follows:

(E2) Had Darwin not lived in accordance with the values of the Victorian society, his evolutionary framework would not have been accepted.

Which explanation, E1 or E2, should we prefer? One could argue (assume this for the sake of illustration) as follows: There is an asymmetry between E1 and E2. It can be seen if we consider the following hypotheses: (I) Theory $\mathrm{T}$ is accepted if it is fruitful, and (II) Theory $\mathrm{T}$ is accepted if it is formulated by a scientist living in accordance with the moral values of the society. There have been theories that have been accepted due to their fruitfulness despite the moral condemnation of the scientist. The case of Galileo Galilei is probably the best known. ${ }^{24} \mathrm{E} 1$ and the associated possible-cause hypotheses (I) seem to deserve their place in our explanatory resources. Producing fruitful results seems to be much more invariantly connected with the acceptance of a theory than the moral virtues of scientists. In Darwin's case, the close connection between fruitful scientific practice and moral virtues was rather coincidental.

Of course, the argument (again produced for the sake of illustration) continues, cases such as Lysenkoism seem to indicate that the moral or political values of scientists sometimes do, in fact, matter more than the fruitfulness of a theory. ${ }^{25}$ Therefore, it remains (to some extent) an open question whether fruitfulness or values are more important in the development of science. This kind of open-endedness is not a philosophical problem. Moreover, it seems safe to conjecture that values play an important role with respect to the short-term acceptance but fruitfulness matters more in the long term. After all, Lysenko's theories are now rejected but Darwin's ideas live on in science.

\footnotetext{
${ }^{24}$ See McMullin (1998) discussing the condemnation of Galileo.

25 See deJong-Lambert and Krementsov (2017) for discussions about Lysenkoism. The Michurinist biology associated with Lysenkoism "openly contradicted the basic tenets of genetics, including Gregor Mendel's laws, Thomas Morgan's chromosomal theory, and the concept of the gene as a material unit of heredity, and supported the Lamarckian idea of the inheritance of the acquired characteristics" (Ibid., 5). Yet, "with the Cold War reaching a crescendo over the status of divided Germany and its capital, Berlin, Lysenko managed to attract Stalin's personal attention to his struggle with geneticists and to secure the Soviet leader's personal support" (Ibid., 8). Soon "the 'undivided rule of Michurinist biology' had indeed been established" (Ibid., 9).
} 
I hope that this brief example illustrates how explanatory resources can be managed and which kind of general considerations play a role in that process. We saw that historiographical progress can be made by seeking widely applicable factors (contra strong localism) but the incorporation of those factors into our explanatory resources requires that we study their applicability in particular historical cases (contra universalist top-down thinking).

2. Whereas explanatory resources guide historiographical studies globally by suggesting which questions are asked and how answers are unified, explanatory depth is a notion that is related to a particular explanandum. The idea behind the notion is that sometimes one explanandum can be explained in different ways and we can compare the depths of different explanantia. There are many dimensions of explanatory depth and they are all related to the ability to answer what-if questions (Hitchcock and Woodward 2003). Roughly, the more answers that an explanation gives to such questions, and the more interesting and accurate the answers are, the better the explanation. Assume that every explanation cites unique factors. What should the what-if questions be about in such case? If they are about unique factors that never existed (by definition, as what-if questions are about counterfactual alternatives to actual events), it seems difficult to understand why we want deeper explanations. The more natural view is that the questions are about the kinds of things that we are more generally interested in and whose causal roles we would like to understand. If we accept this, explanatory depth and explanatory resources are fruitfully connected: deep explanations are applicable to different cases that we are interested in and therefore provide possible-cause hypotheses. The deeper the explanation, the more it tells about interesting cases which did not actualize in a particular historical situation but which may actualize in other historical situations. This means that our search for deeper explanations depends on the possibility of such hypotheses. One cannot achieve deeper explanations without possible-cause hypotheses. As long as we do not abandon the idea of explanatory depth, we must assume that there are possible-cause hypotheses and therefore general considerations.

Notice that once we distinguish between unique causal configurations and conceptual uniqueness, local explanations can be explanatorily deep. If local explanations cite unique causal configurations, they are able to answer what-if questions concerning that configuration. Moreover, explanatory depth and the degree of contingency are connected (but not equated) once we note that (i) the degree of contingency increases when there are many plausible changes in the history that would have changed the outcome, and (ii) the more we are able to track those changes (i.e. answer what-if questions), the deeper is the explanation that we provide. If an outcome depended on many factors, then we have the option to cite many of those factors and deepen our explanation. ${ }^{26}$

3. Not only are our what-if questions but also our explanation-seeking questions themselves are based on general considerations. Historians do not explain everything and they cannot explain everything. Explananda must be chosen and such choices are value-driven. One can choose an explanandum randomly, but such a random choice would leave the historiographical study completely irrelevant for other scholars and wider audiences. It is necessary that historians make judgements concerning the significance of different explananda. Such judgements could be based on intuition;

\footnotetext{
${ }^{26}$ See also Woodward (2018, Appendix 2) discussing similar (perhaps counterintuitive) issue.
} 
however it seems that we are able to justify the significance of an explanandum in many cases. That justification must be derived from considerations of a general kind: How is this explanandum related to other significant explananda? How is it related to our wider concerns as human beings? Moreover, when such general considerations are applied to a particular explanandum, the explanandum must be described in general terms. For example, it is impossible to evaluate the significance of "Galileo did A by Bing”, where A and B are a unique act and a unique attribute of such act. ${ }^{27}$ However, we are able to evaluate the significance of "Galileo described the motion of falling bodies by using mathematical formulas". Historiography requires the use of general considerations and therefore a categorizations of factors.

We have seen that there are three ways in which generalizations and general considerations play a fundamental role in the methodologically sound historiography of science. Perhaps additional ways can be found. However, this already shows that strong localism is incompatible with healthy historiography. Strong localism implies that no such general considerations are possible. The alternative to that position was formulated in the previous section. Following that explication, we can think of local explanations as having the form:

$X$ rather than $Y$ because $(Z$ and $B)$ rather than $[(W$ and $B)$ or $(Z$ and $H)]$, where $Z=$ factor $f_{1}$ is in location $L, B=f_{2}$ in $L, W=f_{1}$ in $L^{*}$, and $H=f_{2}$ in $L^{* *}$.

In other words: had either $\mathrm{f}_{1}$ been in $\mathrm{L}^{*}$ or $\mathrm{f}_{2}$ in $\mathrm{L}^{* *}, \mathrm{Y}$ would have been the case.

For example, a bird was spotted in New York because an ornithologist was on the building $\mathrm{A}$ and the bird was on A; had the bird or the ornithologist been on another building, the bird would not have been spotted.

Now, it is possible that ( $\mathrm{Z}$ and $\mathrm{B}$ ) explain only $\mathrm{X}$ and nothing else in the history of science; yet $f_{1}$ and $f_{2}$ might be factors that fall under general categories and deserve their place in our explanatory resources since the combinations of factors $f_{1}$ and $f_{2}$ with other factors $f_{3}$ and $f_{4}$, such as $\left(f_{1}\right.$ and $\left.f_{3}\right)$ and $\left(f_{2}\right.$ and $\left.f_{4}\right)$, are explanatory. "That there was a bird" and "that there was an ornithologist" can explain many things: for example that a cat runs $\left(f_{3}=\right.$ there was a cat) or that a new species was found $\left(f_{4}=\right.$ there was a bird of the species $\mathrm{S}$ ). There is no incompatibility between local explanations and causal generalizations, once we accept the explication formulated in the previous section. We need causal generalizations. Therefore, we need to accept that explication rather than strong localism.

\section{Conclusion}

Even if there are no unique factors, there can be local explanations: a local explanation points out a set of factors such that had any of the factors been located differently, the outcome would have been different. The co-occurrence of such factors can be a unique occurrence in itself. Here universalism, in the form of more-and-more generally

\footnotetext{
${ }^{27}$ One cannot answer: "Tell me what A and B are and I will tell you if they are significant", since any informative answer would require some categorization of $\mathrm{A}$ and $\mathrm{B}$ that goes beyond them being $\mathrm{A}$ and $\mathrm{B}$.
} 
applicable factors, and localism are connected: the same factors can exist in many locations where science is produced but the exact co-occurrences of such factors can be unique. Moreover, such a co-occurrence might be fragile: some of the factors could perhaps have easily ended in a different location and therefore the course of history could have changed, making the present situation contingent on the co-occurrence. Universalism is correct in insisting upon the use of general categories but wrong in denying unique causal configurations; localism is correct in its claim of unique causal configurations but wrong if it insists on conceptual uniqueness.

Moreover, I have argued that it is methodologically necessary that a general explanatory framework and the explanations of particular occurrences guide each other. The illustration focusing on Bellon's paper did not directly involve a local explanation, but we can note that focusing on a particular historical context is necessary in the historiography of science in order to build a good stock of explanatory resources that have a more general scope. This is where the localist tradition is on the right track, methodologically speaking. It carries some ingredients for "well corroborated (general) knowledge, the validity of which extends beyond a particular locality" (Kuukkanen 2012 , 484). Surely, localism must be supplemented with general considerations to achieve such knowledge but local explanations, qua explanations of particular occurrences, can be methodologically highly valuable. Universalism and localism are therefore symbiotic.

However, we need to note that local explanations, as explicated here, are not methodologically preferable to every other kind of explanations, only to a crude universalism that attempts to capture science once and for all by a limited set of factors. This might not be too great an achievement, as it is not clear whether such crude universalism has had any supporters. It might be that what seems like universalism is just a different way of approaching the same thing, that the particular and the general must be connected in healthy historiography. Be that as it may, we now see why someone, taking crude universalism as a serious threat, can point out that localism is preferable to such universalism. Moreover, we see why trivial localism should not be accepted. Even crude universalists can claim that (i) explanatory factors are always instantiated in a particular location but (ii) the factors so located are always the same and therefore universal. If trivial localism is accepted, then local explanations are not methodologically preferable to anything (as crude universalism would also provide local explanations in the trivial sense).

Funding Open access funding provided by University of Turku (UTU) including Turku University Central Hospital.

Open Access This article is licensed under a Creative Commons Attribution 4.0 International License, which permits use, sharing, adaptation, distribution and reproduction in any medium or format, as long as you give appropriate credit to the original author(s) and the source, provide a link to the Creative Commons licence, and indicate if changes were made. The images or other third party material in this article are included in the article's Creative Commons licence, unless indicated otherwise in a credit line to the material. If material is not included in the article's Creative Commons licence and your intended use is not permitted by statutory regulation or exceeds the permitted use, you will need to obtain permission directly from the copyright holder. To view a copy of this licence, visit http://creativecommons.org/licenses/by/4.0/. 


\section{References}

Bellon, R. (2011). Inspiration in the harness of daily labor: Darwin, botany, and the triumph of evolution, 1859-1868. Isis: A Journal of the History of Science, 102, 393-420.

Daston, L. (2009). Science Studies and the History of Science. Critical Inquiry, 35(4), 798-813.

Davidson, D. (1967). Causal Relations. Journal of Philosophy, 64, 691-703.

deJong-Lambert, W., and Krementsov, N. (2017). “Lysenkoism' Redux: Introduction”. In deJong-Lambert, William \& Krementsov, Nikolai (eds.). The Lysenko controversy as a global phenomenon, volume 1: Genetics and agriculture in the Soviet Union and beyond. Palgrave Macmillan.

Elliot, P. (2003). "Erasmus Darwin, Herbert Spencer, and the origins of the evolutionary worldview in British provincial scientific culture, 1770-1850". Isis, 94(1).

Galison, P. (1997). "Material culture, theoretical culture and delocalization". In John Krige \& Dominique Pestre (Eds.), Science in the twentieth century. 669-683.

Galison, P. (2008). Ten problems in history and philosophy of science. Isis, 99(1), 111-124.

Golinski, J. (2012). Is it time to forget science? Reflections on singular science and its history. Osiris, 27(1), 19-36.

Hempel, C., \& Oppenheim, P. (1948). Studies in the logic of explanation. Philosophy of Science, 15, 135-175.

Hempel, C. G. (1942). The function of general laws in history. Journal of Philosophy, 39(2), 35-48.

Hitchcock, C., \& Woodward, J. (2003). Explanatory generalizations, part II: Plumbing explanatory depth. Noûs, 37(2), 181-199.

Kinzel, K. (2015). State of the field: Are the results of science contingent or inevitable? Studies in History and Philosophy of Science Part A, 52, 55-66.

Kitcher, P. (1989). "Explanatory unification and the causal structure of the world". In Kitcher, Philip \& Salmon, Wesley C. (ed.) Scientific Explanation. Minnesota Studies in Philosophy of Science. University of Minnesota Press, 410-505.

Kohler, R., \& Olesko, K. (2012). Introduction: Clio meets science. Osiris, 27(1), 1-16.

Krige, J. (2001). Distrust and discovery: The case of the heavy bosons at CERN. Isis, 92(3), 517-540.

Kuhn, T. S. (1977). "Objectivity, value judgment, and theory choice”. In The Essential Tension. University of Chicago Press. 320-39.

Kuukkanen, J.-M. (2011). I am knowledge. Get me out of here! On localism and the universality of science. Studies in History and Philosophy of Science Part A, 42(4), 590-601.

Kuukkanen, J.-M. (2012). Senses of Localism. History of Science, 50(4), 477-500.

Lakatos, I. (1978). The methodology of scientific research Programmes. Cambridge University Press.

Laudan, L. (1977). Progress and its problems: Toward a theory of scientific growth. University of California Press.

McMullin, Ernan (1998). "Galileo on science and scripture”. In Machamer, Peter (ed.). The Cambridge companion to Galileo. Cambridge University Press.

Rée, J. (1991). The vanity of historicism. New Literary History, 22(4), 961-983.

Secord, J. (2004). Knowledge in transit. Isis, 95(4), 654-672.

Soler, L., Trizio, E., and Pickering, A. (2015). Science as it could have been. Discussing the Contingency/ Inevitability Problem. University of Pittsburgh Press.

Hume, D. (2007). A Treatise of Human Nature. Clarendon Press. Edited by David fate Norton and Mary J. Norton.

Virmajoki, V. (2018). Could science be interestingly different? Journal of the Philosophy of History, 12(2), 303-324.

Virmajoki, V. (2019). Cementing science. Understanding science through its development. https://www. utupub.fi/handle/10024/147334.

Virmajoki, V. (2020). What should we require from an account of explanation in historiography? Journal of the Philosophy of History. Forthcoming.

Woodward, J. (2003). Making things happen. A Theory of Causal Explanations. Oxford University Press.

Woodward, J. (2018). Explanatory autonomy: The role of proportionality, stability, and conditional irrelevance. Synthese. https://doi.org/10.1007/s11229-018-01998-6.

Publisher's note Springer Nature remains neutral with regard to jurisdictional claims in published maps and institutional affiliations. 